\title{
Dual-Wide Band Stub Loaded Step Impedance Resonator Filter with Folded Meander Couple Lines
}

\author{
Y. Tu ${ }^{1}$, Yasir I. A. Al-Yasir ${ }^{1, *}$, Abdolrauf Alhaddad ${ }^{1,2}$, Naser Ojaroudi Parchin ${ }^{1}$, Ahmed \\ Abdulkhaleq ${ }^{1,3}$, Falih Mahdi Alnahwi ${ }^{4}$, and Raed Abd-Alhameed ${ }^{1}$ \\ \{Y.I.A.Al-Yasir@bradford.ac.uk\} \\ ${ }^{1}$ Faculty of Engineering and Informatics, University of Bradford, Bradford, UK \\ ${ }^{2}$ Converting Industries Company, Light industrial Area, Royal commission, Yanbu, Yanbu Alsinaya \\ 41912, P.O. Box 32171, Saudi Arabia \\ ${ }^{3}$ SARAS Technology, Leeds, UK \\ ${ }^{4}$ Department of Electrical Engineering, University of Basrah, Basrah, Iraq
}

\begin{abstract}
In this paper, a novel multi-standard filter with the size of only $4.6 \mathrm{~mm} \times 41.65 \mathrm{~mm}$ and a thickness of $0.635 \mathrm{~mm}$ is presented. This filter is capable of generating two wide operating bands that effectively cover the GSM/UMTS/GPS/IEEE 802.11a operations in mobile devices, which include GSM1800 $(1710-1880 \mathrm{MHz})$, GSM1900 (1850-1990 MHz), UMTS (1920-2170 MHz), GPS (frequency band cantered at $5.75 \mathrm{GHz}$ ) and IEEE $802.11 \mathrm{a}$ (frequency band cantered at $5.8 \mathrm{GHz}$ ) bands. The proposed multi-standard filter's wide bandwidths at the low and high frequency are attributed to the mutual coupling of the modified SIR resonators. Meanwhile, in band and out of band performances of the proposed filter are enhanced by novel folded structure and even and odd phase velocity compensation technique using shifted coupled lines. Because there is no via hole or defect ground structure included in the filter structure, the structure is relatively simple and easily realized.
\end{abstract}

Keywords: multi-standard, filter, IEEE, SIR, bandwidth.

\section{Introduction}

Radio frequency noise is a serious problem in current applications of wireless systems such as green communications and wide-band radar applications [1-15]. Microstrip bandpass filters (BPF) are widely used to defeat noise and undesirable waves in multiple communication applications [16-34], basically in RF and microwave communications because of their effective filtering of harmonic signals. With the development of wireless communication systems, multistandard internal filters have become a necessity for the state-of-the-art multifunction "smart phones" and wireless frontends for the mobile devices. Such filters are generally required to be capable of covering the frequency bands of Global System for Mobile Communication (GSM: 1800/1900 MHz etc.), Universal Mobile Telecommunications System (UMTS: 1710-1880/18501990/1920-2170 MHz etc.) and Global Positioning System (GPS) (frequency bands centred at $1.57 \mathrm{GHz}$ ). Furthermore, the ever increasing implementation of Wireless Local Area Network (WLAN) such as Wi-Fi devices further increases the IEEE 802.11a bandwidth requirement in order to cover the bands centered at $5.8 \mathrm{GHz}$. 
In the above mentioned dual-band filters, most of them with a miniaturized size fail to cover the required frequency bands, especially at the lower frequency band due to the narrower dual bandwidth [17], [18], [19], [20], [24-30] or require a considerable filter size or thickness, which usually makes them difficult to integrate within mobile devices or portable wireless modules [18], [24]. In this paper, we propose a novel multi-standard filter with the size of only $4.6 \mathrm{~mm} \times 41.65 \mathrm{~mm}$ and a thickness of $0.635 \mathrm{~mm}$. This filter is capable of generating two wide operating bands that effectively cover the GSM/UMTS/GPS/IEEE 802.11a operations in mobile devices, which include GSM1800, GSM1900, UMTS, GPS and IEEE 802.11a bands.

\section{Filter configuration}

\subsection{Stepped impedance resonators with folded meander couple lines}

The geometry of the presented multiband filter is illustrated in Fig. 1. The modified stepped impedance resonators (SIRs) of the proposed filter are improved from the traditional a quarter wavelength SIR, which is shown in Fig. 2. Because traditional a quarter wavelength SIR can generate tunable first spurious frequency, the proposed filter utilizes a pair of SIRs to form dual wide bands which are composed of fundamental resonance frequency band and the first spurious frequency band. Because the traditional a quarter wavelength SIR has the disadvantage of generating high order spurious frequency response, which would deteriorate filter out of band performance. To overcome this disadvantage, we propose a novel structure using folded meander couple lines instead of traditional a quarter wavelength SIR couple lines to suppress high order spurious frequency and improve out of band performance. In this paper, the modified stepped impedance strips are fed by two $50 \Omega$ microstrip feed lines. The width (W1) and length (H1) of the $50 \Omega$ feed line is $0.6 \mathrm{~mm}$ and $1.2 \mathrm{~mm}$, respectively.

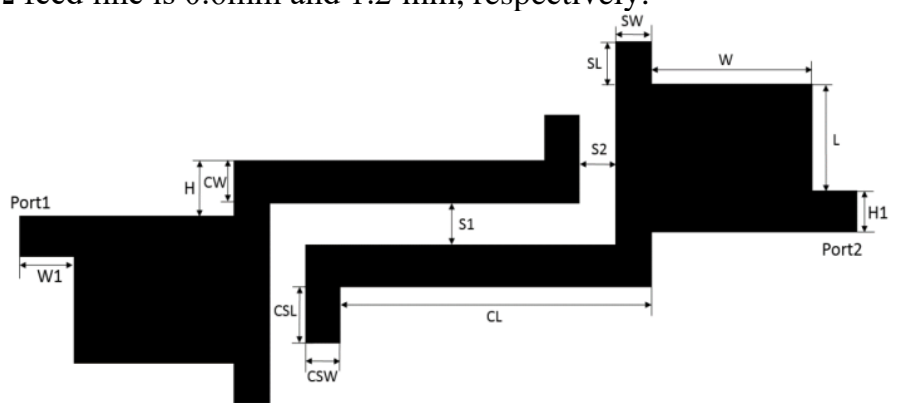

Fig. 1. The geometry of the introduced dual-wide band BPF.

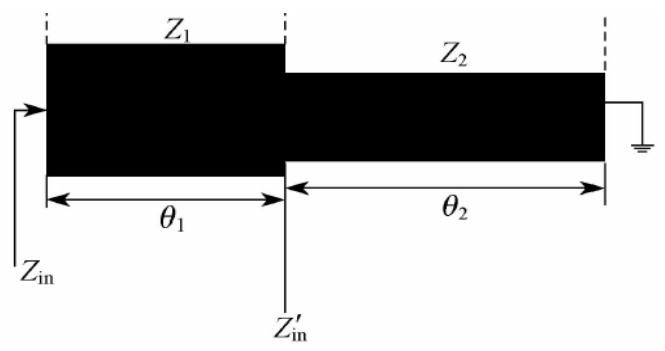

Fig. 2. The structure of the a quarter wavelength SIR. 
By tuning the value of impedance ratio, the first spurious frequency can be tuned. In this paper, the fundamental resonance frequency and the first spurious frequency of the dual-wide band filter is set as $1.9 \mathrm{GHz}$ and $5.8 \mathrm{GHz}$, respectively. By careful calculations, the width $(\mathrm{W}+\mathrm{SW})$ and length $(\mathrm{L}+\mathrm{H} 1)$ of the high characteristic impedance part is set as $1.7 \mathrm{~mm}$ and $11.2 \mathrm{~mm}$, respectively. The width $(\mathrm{CW})$ and length $(\mathrm{CL}+\mathrm{CSW})$ of the low characteristic impedance part is set as $0.4 \mathrm{~mm}$ and $16.5 \mathrm{~mm}$, respectively. The function of the different folded meander couple lines and comparison to the case without folded couple line are illustrated in Fig. 3. From Fig.3, when there is a distance $(\mathrm{H})$ between of low characteristic impedance line and high characteristic impedance line, we can see that when the value of $\mathrm{H}$ becomes larger, the return loss of first and high order spurious frequency become larger. Utilizing this feature, we can suppress high order spurious frequency response by tuning the value of $\mathrm{H}$. In this work, the value of $\mathrm{H}$ is set as $0.52 \mathrm{~mm}$.

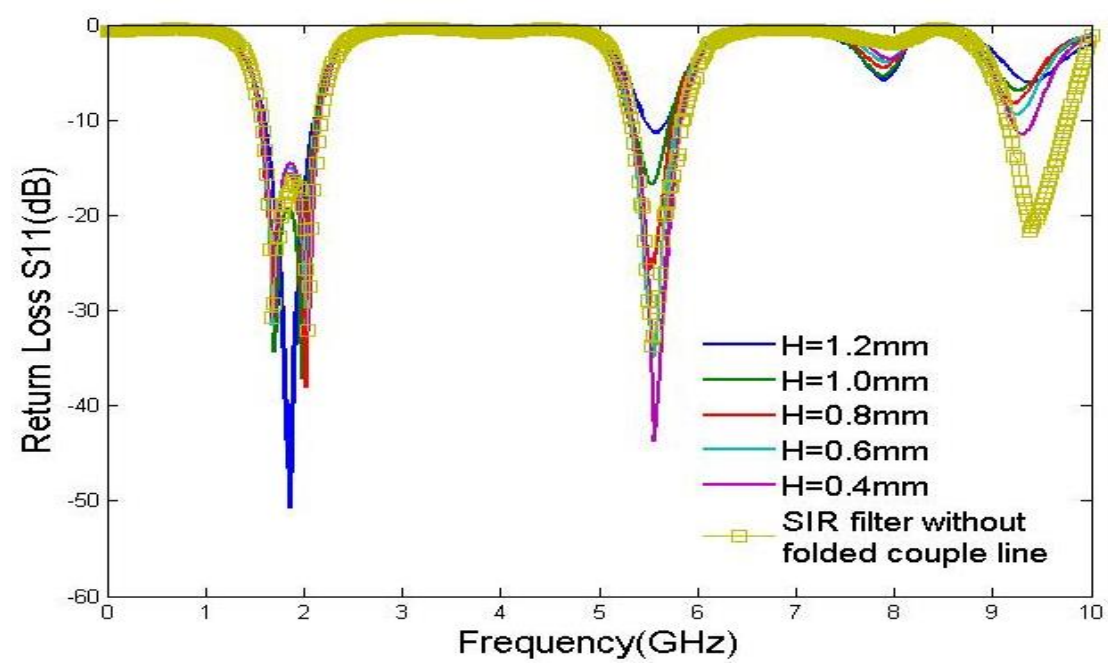

Fig. 3. The function of the different folded meander couple lines and comparison to the case without folded couple line.

\subsection{The even and odd phase velocity compensation technique in the one quarter wavelength type resonator}

Because the coupled lines fabricated with microstrip circuits would generate unequal even- and odd- mode phase velocities, the filter's performance, shown as dotted lines in Fig. 4, would be slightly different from the theoretically predicted results [35]. Traditionally, in order to compensate the unequal even- and odd-mode phase velocities resulted from the coupled lines fabricated with a half wavelength resonator circuits, the capacitive [36] or inductive [37] compensation, corrugate lines [38], or wiggly lines [39] have been proposed. However, these design procedures are relatively complicated. Moreover, a half wavelength resonator circuits usually occupy relatively larger size than a quarter wavelength resonator circuits. In this work, we adopt even- and odd-mode phase velocities compensation technique with shifted coupled lines [40] for the first time in the quarter wavelength type resonator to solve the disadvantages mentioned above.

With the shifted couple lines, an additional coupling will be resulted from CSL being coupled to modify stepped impedance resonator, which is shown in Fig.1. Hence, the spurious 
performance is improved. Moreover, the spurious peak can be suppressed so that the response represented by the dashed lines in Fig. 4 is observed. Furthermore, with the coupled line's insertion loss as zero, the coupled length for the shifted coupled line can be obtained from:

$$
\frac{Z_{0 e}}{Z_{0 o}}=\frac{\sin \beta_{e} l}{\sin \beta_{o} l}
$$

Where and are the even- and odd-mode characteristic impedance, respectively. For simplicity we set widths of shifted coupled lines as $0.4 \mathrm{~mm}$ and lengths as $0.3 \mathrm{~mm}$.

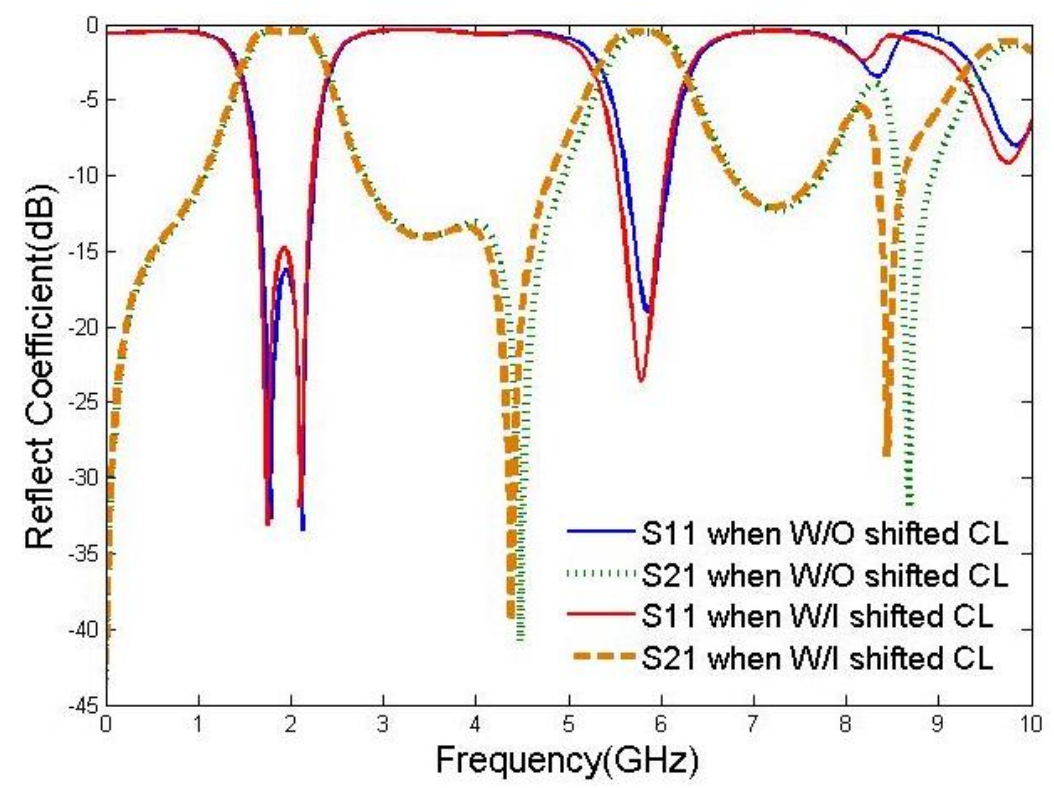

Fig. 4. The comparison between reflection coefficients S21, S11 with and without shifted couple line.

\section{The effect of loaded open-stub}

As can be seen in Fig. 4,the even- and odd-mode phase velocities compensate technique using shifted coupled lines has an impact to fundamental resonance frequency in this design, which worsen the return loss performance of fundamental resonance frequency. In order to solve this problem, we compensate the return loss of fundamental resonance frequency as well as the first spurious frequency by using the loaded open stub. As can be seen in Fig.5, because of the existence of the loaded open stub, return loss performance of fundamental resonance frequency become better compared to that in Fig. 4. and the return loss of first spurious frequency become less when the length of loaded open stub become longer, while the return loss of high order spurious frequency remains almost unchanged when the length of loaded open stub varies. By using these features, the width (SW) and length (SL) of the open stub is set as $0.4 \mathrm{~mm}$ and $0.25 \mathrm{~mm}$ in this design, respectively. Fig. 6 shows two cases when the design has no loaded open stub and has loaded open stub with parameters of width $(\mathrm{SW})=0.4 \mathrm{~mm}$ and length $(\mathrm{SL})=0.25 \mathrm{~mm}$. 


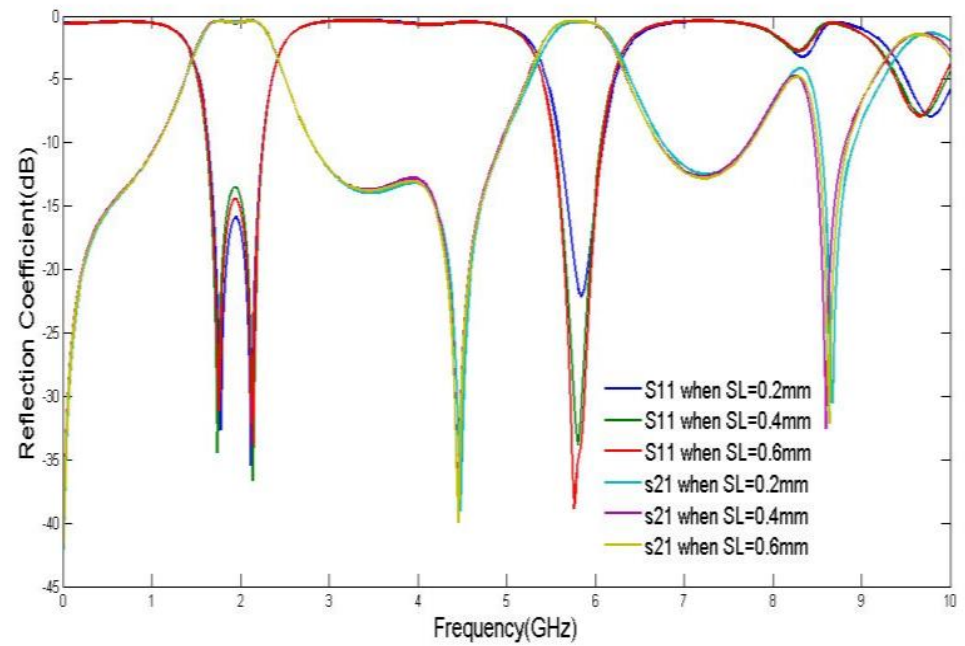

Fig. 5. The relationship between reflection coefficient and the length of loaded open-stub line.

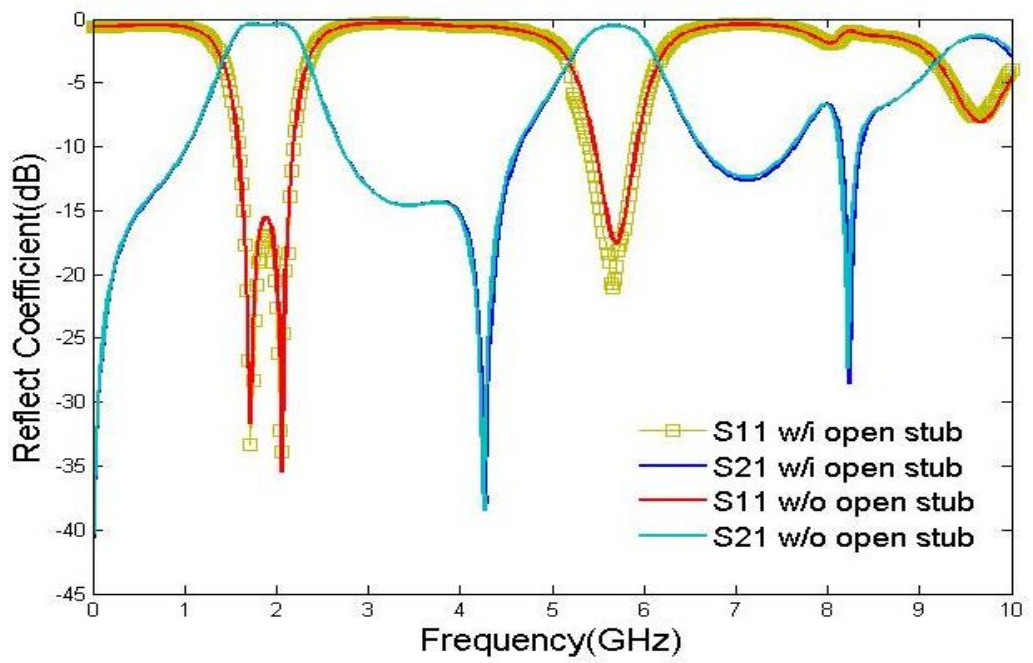

Fig. 6. The influence of the open stub to the proposed dual-wide band BPF.

\section{The isolation between bands}

In addition, the even- and odd-mode circuit is utilized for the proposed configuration to locate the transmission zeroes. Suppose the transmission zeroes is derived from the couple line. In the model, three transmission zeroes are generated as $0 \mathrm{GHz}, 4.42 \mathrm{GHz}$ and $8.52 \mathrm{GHz}$, which are shown in Fig. 6. These transmission zeroes provides well isolation between the desired bands, suppression of out of band interruption and enhancement of the frequency selectivity. Fig.7 shows the final results of the proposed dual-band filter with substrate's dielectric constant of 
10.2. The vertical and horizontal length of the gap between two resonance pair is $\mathrm{S} 1=0.2 \mathrm{~mm}$ and $\mathrm{S} 2=0.65 \mathrm{~mm}$, respectively.

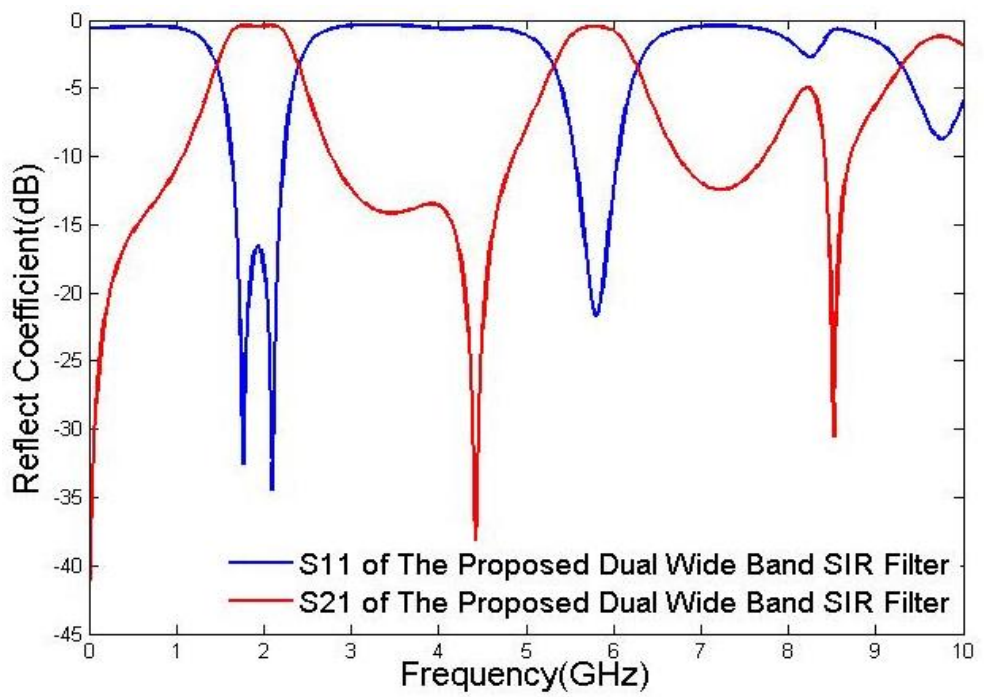

Fig. 7. S-parameter of the designed dual-band BPF.

\section{Conclusion}

A novel multi-standard dual-wide band filter with a compact size is designed and developed for wireless communication systems. This proposed filter covers a fundamental bandwidth of $605.9 \mathrm{MHz}$ with fractional bandwidth(FBW) of $31.4 \%$ centered at the $1.9 \mathrm{GHz}$ band and first spurious bandwidth of $501 \mathrm{MHz}$ with FBW of $8.6 \%$ centered at the $5.8 \mathrm{GHz}$, while occupy a compact area of only $4.6 \mathrm{~mm}$ by $41.65 \mathrm{~mm}$. By utilizing novel stepped impedance resonators with folded meander couple lines as well as even and odd phase velocity compensation technique in a quarter wavelength type resonator, high order spurious frequency performance is enhanced considerably. With the adaptation of loaded open stub, the return loss performance of the fundamental resonance frequency and the first spurious frequency improves successfully. The multi-standard filter is designed, described and fully simulated. The Ansoft HFSS software simulated results agree well with the theory predictions. The featured broad bandwidths over dual applicable frequency bands and the miniaturized size of the proposed filter make it very promising for applications in multi-standard wireless communication.”

Acknowledgments. This project has received funding from the European Union's Horizon 2020 research and innovation programme under grant agreement H2020-MSCA-ITN-2016 SECRET-722424.

\section{References}

[1] A. Hussaini, Y. Al-Yasir, k. Voudouris, B. Mohammed, R. A. Abd-Alhameed, H. Mohammed, I. Elfergani, A. Abdullah, D. Makris, J. Rodriguez, J. M. Noras, C. Nche, and M. Fonkam, Green Flexible RF for 5G. Fundamentals of 5G Mobile Networks, John Wiley and Sons, pp. 241-272, 2015.

[2] Yasir I.A. Al-Yasir, Hasanain A.H. Al-Behadili, Baha A. Sawadi, Naser Ojaroudi Parchin, Ahmed M. Abdulkhaleq, Abdulkareem S. Abdullah and Raed A. Abd-Alhameed (September 26th 2019). New 
Radiation Pattern-Reconfigurable 60-GHz Antenna for 5G Communications, IntechOpen, Available from: $\quad$ https://www.intechopen.com/online-first/new-radiation-pattern-reconfigurable-60-ghzantenna-for-5g-communications.

[3] Y. Al-Yasir et al., "Compact tunable microstrip filter with wide-stopband restriction and wide tuning range for 4g and 5g applications," The IET's Antennas and Propagation Conference, 2019, pp. 1-6.

[4] Abdulraheem, Y.; Abdullah, A.S.; Mohammed, H.J.; Mohammed, B.; Abd-Alhameed, R.A.; Noras, J. Design of Radiation Pattern-Reconfigurable 60-GHz Antenna for 5G Applications. J. Telecommun. 2014, 27, 7-11.

[5] H. J. Mohammed et al., "Evaluation of genetic algorithms, particle swarm optimisation, and firefly algorithms in antenna design," 2016 13th International Conference on Synthesis, Modeling, Analysis and Simulation Methods and Applications to Circuit Design (SMACD), Lisbon, 2016, pp. 1-4.

[6] Y. I. A. Al-Yasir and R. Abd-Alhameed, " New multi-standard dual-wideband and quad-wideband asymmetric step impedance resonator filters with wide stop band restriction," International Journal of RF and Microwave Computer-Aided Engineering, vol. 29, no. 8, p. 1-17, 2019.

[7] Y. I. A. AI-Yasir, N. Ojaroudi Parchin, A. Alabdullah, W. Mshwat, A. Ullah and R. Abd-Alhameed, "New Pattern Reconfigurable Circular Disk Antenna Using Two PIN Diodes for WiMax/WiFi (IEEE 802.11a) Applications," 2019 16th International Conference on Synthesis, Modeling, Analysis and Simulation Methods and Applications to Circuit Design (SMACD), Lausanne, Switzerland, 2019, pp. 53-56

[8] Y. I. A. Al-Yasir et al, "Design, simulation and implementation of very compact dual-band microstrip bandpass filter for 4G and 5G applications," 2019 16th International Conference on Synthesis, Modeling, Analysis and Simulation Methods and Applications to Circuit Design (SMACD), Lausanne, Switzerland, 2019, pp. 41-44.

[9] Y. I. A. Al-Yasir, N. O. Parchin, A. Alabdallah, A. M. Abdulkhaleq, R. A. Abd-Alhameed and J. M. Noras, "Design of Bandpass Tunable Filter for Green Flexible RF for 5G," 2019 IEEE 2nd 5G World Forum (5GWF), Dresden, Germany, 2019, pp. 194-198.

[10] Y. I. A. Al-Yasir et al., "Design, Simulation and Implementation of Very Compact Open-loop Trisection BPF for 5G Communications," 2019 IEEE 2nd 5G World Forum (5GWF), Dresden, Germany, 2019, pp. 189-193.

[11] Y. Al-Yasir, A. S. Abdullah, N. Ojaroudi Parchin, R. A. Abd-Alhameed, and J. M. Noras, "A New Polarization-Reconfigurable Antenna for 5G Applications," Electronics, vol. 7, no. 11, p. 293, 2018.

[12] Al-Yasir Y.I.A. et al. (2019) A New Polarization-Reconfigurable Antenna for 5G Wireless Communications. In: Sucasas V., Mantas G., Althunibat S. (eds) Broadband Communications, Networks, and Systems. BROADNETS 2018. Lecture Notes of the Institute for Computer Sciences, Social Informatics and Telecommunications Engineering, vol 263. Springer, Cham.

[13] Y. I. A. Al-Yasir et al., "A Differential-Fed Dual-Polarized High-Gain Filtering Antenna Based on SIW Technology for 5G Applications," 2020 14th European Conference on Antennas and Propagation (EuCAP), Copenhagen, Denmark, 2020, pp. 1-5.

[14] Y. I. A. Al-Yasir et al., "Design of multi-standard single/tri/quint-wideband asymmetric steppedimpedance resonator filters with adjustable TZs," IET Microwaves, Antennas \& Propagation, vol. 13, no. 10, pp. 1637-1645, 14 Aug. 2019.

[15] Y. I. A. Al-Yasir et al., " New High-Gain Differential-Fed Dual-Polarized Filtering Microstrip Antenna for 5G Applications," 2020 13th European Conference on Antennas and Propagation (EuCAP), Copenhagen, Denmark, 2020, pp. 1-5.

[16] J.-S. G. Hong and M. J. Lancaster, Microstrip Filters for RF/Microwave, vol. 167, John Wiley and Sons, 2004.

[17] Bian Wu; Chang-Hong Liang; Pei-Yuan Qin ; Qi Li Compact Dual-Band Filter Using Defected Stepped Impedance Resonator. IEEE Microwave and Wireless Components Letters, Vol.18.no.10, 2008, pp.674-676.

[18] Wei-Shin Chang ; Chi-Yang Chang. Analytical Design of Microstrip Short-Circuit Terminated Stepped-Impedance Resonator Dual-Band Filters. IEEE Transactions on Microwave Theory and Techniques, Vol.59, no.7, 2011, pp. 1730-1739. 
[19] Li Gao ; Xiu Yin Zhang. High-Selectivity Dual-Band Band pass Filter Using a Quad-Mode Resonator with Source-Load Coupling. IEEE Microwave and Wireless Components Letters, Vol.23, no. 9, Page(s): 474 - 476, 2013.

[20] Shou-Jia Sun ; Tao Su ; Kun Deng ; Bian Wu ; Chang-Hong Liang. Compact Microstrip Dual-Band Bandpass Filter Using a Novel Stub-Loaded Quad-Mode Resonator. IEEE Microwave and Wireless Components Letters, Vol.23 no9, pp. 465- 467, 2013.

[21] Y. Al-Yasir, N. Ojaroudi Parchin, R. Abd-Alhameed, A. Abdulkhaleq and J. Noras, "Recent Progress in the Design of 4G/5G Reconfigurable Filters" Electronics", vol. 8, no. 1, Jan. 2019.

[22] Y. Al-Yasir, Y. Tu, N. Ojaroudi Parchin, I. Elfergani, R. Abd-Alhameed, J. Rodriguez, J. Noras, "Mixed-coupling multi-function quint-wideband asymmetric stepped impedance resonator filter" Microw. and Opt. Tech. Lett. Vol. 61, no. 5, pp1181-1148, Jan. 2019.

[23] Y. Al-Yasir, R. A. Abd-Alhameed, J. M. Noras, A. Abdulkhaleq and N. Ojaroudi Parchin, "Design of Very Compact Combline Band-Pass Filter for 5G Applications," Loughborough Antennas \& Propagation Conference, Loughborough, UK, 2018.

[24] Y. C. Chiou, C. Y. Wu, and J. T. Kuo. New miniaturized dual-mode dual-band ring resonator band pass filter with microwave C-sections. IEEE Microwave Wireless Component Letter .vol. 20, no. 2, pp. 67-69, Feb. 2009.

[25] S. Luo, L. Zhu, and S. Sun. A dual-band ring resonator band pass filter based on two pairs of degenerate modes. IEEE Transaction on Microwave Theory and Techniques .vol. 58, no. 12, pp. 3427 3432, Dec. 2010

[26] S. Sun. A dual-band band pass filter using a single dual-mode ring resonator. IEEE Microwave Wireless Component Letter. vol. 21, no. 6, pp.298-300, Jun. 2011.

[27] Al-Yasir, Y.I.A.; A. Alhamadani, H.; Kadhim, A.S.; Ojaroudi Parchin, N.; Saleh, A.L.; Elfergani, I.T.E.; Rodriguez, J.; Abd-Alhameed, R.A. Design of a Wide-Band Microstrip Filtering Antenna with Modified Shaped Slots and SIR Structure. Inventions 2020, 5, 11.

[28] Y. Sung. Dual-mode dual-band filter with band notch structures. IEEE Microwave Wireless Component Letter. vol. 20, no. 2, pp. 73-75, Feb.2010.

[29] Y. C. Li, H. Wong, and Q. Xue. Dual-mode dual-band filter based ona stub-loaded patch resonator. IEEE Microwave Wireless Component Letter. vol. 21, no. 10, pp. 525-527, Oct. 2011.

[30] R. Zhang, L. Zhu, and S. Luo. Dual-mode dual-band band pass filter using a single slotted circular patch resonator. IEEE Microwave Wireless Component Letter .vol. 22, no. 5, pp. 233-235, May 2012.

[31] Al-Yasir, Y.I.A.; Alkhafaji, M.K.; A. Alhamadani, H.; Ojaroudi Parchin, N.; Elfergani, I.; Saleh, A.L.; Rodriguez, J.; Abd-Alhameed, R.A. A New and Compact Wide-Band Microstrip Filter-Antenna Design for 2.4 GHz ISM Band and 4G Applications. Electronics 2020, 9, 1084.

[32] Al-Yasir, Y.I.A.; Ojaroudi Parchin, N.; Abdulkhaleq, A.M.; Bakr, M.S.; Abd-Alhameed, R.A. A Survey of Differential-Fed Microstrip Bandpass Filters: Recent Techniques and Challenges. Sensors 2020, 20, 2356.

[33] Parchin, N.O.; Al-Yasir, Y.I.A.; Abd-Alhameed, R.A. Microwave/RF Components for 5 G Front-End Systems; Avid Science: Telangana, India, 2019; pp. 1-200.

[34] Y. I. Abdulraheem et al., "Design of frequency reconfigurable multiband compact antenna using two PIN diodes for WLAN/WiMAX applications," in IET Microwaves, Antennas \& Propagation, vol. 11, no. 8, pp. 1098-1105, 2262017.

[35] Shih-Ming Wang ; Chun-Hsiang Chi ; Ming-Yu Hsieh ; Chi-Yang Chang Miniaturized spurious pass band suppression microstrip filter using meandered parallel coupled lines .IEEE Transactions on Microwave Theory and Techniques, Vol.53, no.2, pp.747-753, 2005.

[36] S. L. March, Phase velocity compensation in parallel-coupled microstrip. IEEE MTT-S International Microwave Symposium Digest, pp. 410-413.

[37] R. Phromloungsri, M. Chongcheawchamnan, and I. D. Robertson, Inductively compensated parallel coupled microstrip lines and their applications. IEEE Transactions on Microwave Theory and Techniques, vol.54, no.9, pp.3571-3582, 2006. 
[38] J. T. Kuo, W. H. Hsu, and W. T. Huang, Parallel coupled microstrip filters with suppression of harmonic response. IEEE Microwave and Wireless Components Letters, vol.12, no.10, 2002, pp. 383-385.

[39] T. Lopetegi, M. A. G. Laso, J. Hernandez, M. Bacaicoa, D. Benito, M. J. Garde, M. Sorolla, and M. Guglielmi. New microstrip "wigglyline" filters with spurious pass band suppression. IEEE Transactions on Microwave Theory and Techniques, vol. 49, no. 9, 2001, pp. 1593-1598.

[40] A. Riddle, High performance parallel coupled microstrip filters. IEEE MTT-S International Microwave Symposium Digest, 1988, pp. 427-430. 